\title{
Selective Electrochemical Detection of Epinephrine Using Gold Nanoporous Film
}

\author{
Dina M. Fouad and Waleed A. El-Said \\ Chemistry Department, Faculty of Science, Assiut University, Assiut 71516, Egypt \\ Correspondence should be addressed to Waleed A. El-Said; w.ahmed53@yahoo.com
}

Received 17 July 2016; Accepted 15 August 2016

Academic Editor: Hassan Karimi-Maleh

Copyright (C) 2016 D. M. Fouad and W. A. El-Said. This is an open access article distributed under the Creative Commons Attribution License, which permits unrestricted use, distribution, and reproduction in any medium, provided the original work is properly cited.

\begin{abstract}
Epinephrine (EP) is one of the important catecholamine neurotransmitters that play an important role in the mammalian central nervous system. Therefore, it is necessary to determine the change of its concentrations. Nanoporous materials have wide applications that include catalysis, energy storages, environmental pollution control, wastewater treatment, and sensing applications. These unique properties could be attributable to their high surface area, a large pore volume, and uniform pore sizes. A gold nanoporous layer modified gold electrode was prepared and applied for the selective determination of epinephrine neurotransmitter at low concentration in the presence of several other substances including ascorbic acid (AA) and uric acid (UA). The constructed electrode was characterized using scanning electron microscopy and cyclic voltammetry. The resulting electrode showed a selective detection of epinephrine with the interferences of dopamine and uric acid over a wide linear range (from $50 \mu \mathrm{M}$ to $1 \mathrm{mM}$ ). The coverage of gold nanoporous on the surface of gold electrode represents a promising electrochemical sensor with high selectivity and sensitivity.
\end{abstract}

\section{Introduction}

Epinephrine (EP) is one of the most important catecholamine neurotransmitters, which plays an important role in the transmission of nerve impulse and is associated with a large variety of physiological processes and illnesses. Monitoring the concentration of EP gains great attention since the changes in its concentrations resulted in many diseases such as Parkinsonism, Schizophrenia, and Huntington's disease as well as drug addiction and HIV infection [1-5] and affects many life phenomena. In biological systems, EP frequently exists with dopamine (DA) and uric acid (UA); therefore, it is necessary to selectively detect EP in the presence of different interferences such as DA and UA [69]. For electrochemical sensing, it is important to avoid the overlapping in the electrochemical response of EP and other species due to their close oxidizing potentials. It is difficult to use conventional electrodes for selective determination of EP electrochemically in the presence of DA, UA, and AA, which frequently exist together in biological systems, since at most solid electrodes they are oxidized at a closed potential producing an overlapping voltammetric response.

Application of electrochemical methods proved to be highly sensitive and selective techniques [10-12] for the detection of biological materials $[13,14]$. Many complications face the use of the electrochemical methods such as the influence of many analytes interferences, which may be present at higher concentrations. The use of modified electrodes as biosensors produces several advantages such as the ease of fabrication, the renewable surface, low background current, and also the wide range of potential ranges. Modified electrodes enable the detection of several analytes within different matrices (urine or blood) without separations giving electrical signals at characteristic potentials. Also, the use of these electrodes overcomes the problem of using analytes of a significant electroactivity [15]. In our previous work, we have fabricated several modified electrodes and their applications for detection of many biological targets [16-23]. In recent years, nanomaterials with special physical and chemical properties have been widely applied in chemosensors and 
TABLE 1: Comparison of epinephrine sensor based on gold nanoporous film modified gold electrode with other epinephrine sensors.

\begin{tabular}{|c|c|c|c|}
\hline Electrode & Method & $\operatorname{LOD}(\mu \mathrm{M})$ & Reference \\
\hline Modified carbon nanotubes paste electrode & DPV & 0.09 & {$[38]$} \\
\hline Modified gold electrode & $\mathrm{CV}$ & 0.1 & {$[39]$} \\
\hline Nanodiamond/graphite & LSV & 0.5 & {$[40]$} \\
\hline $\mathrm{ZnO}$ nanoparticle/modified carbon paste electrode & SWV & 0.05 & {$[41]$} \\
\hline Carbon paste electrode modified with iron phthalocyanine & DPV & 0.5 & {$[42]$} \\
\hline Penicillamine self-assembled gold electrode & $\mathrm{CV}$ & 0.1 & {$[43]$} \\
\hline Modified carbon nanotube paste electrode & DPV & 0.035 & {$[44]$} \\
\hline Carbon nanotube modified carbon film electrodes & DPV & 0.9 & {$[45]$} \\
\hline TTAB modified carbon paste electrode & $\mathrm{CV}$ & 0.12 & {$[46]$} \\
\hline Molecularly imprinted polymers & Amperometric & 0.03 & {$[47]$} \\
\hline MWCNT/dopamine dithiocarbamate modified electrode & Amperometric & 11 & {$[48]$} \\
\hline Nanoporous thin Au films & DPV & 2.42 & {$[49]$} \\
\hline Gold nanoporous film modified gold electrode & $\mathrm{CV}$ & 19 & This study \\
\hline
\end{tabular}

biosensors. Nanomaterial-based electrochemical sensing of neurological drugs and neurotransmitters has recently gained great attention [24-26]. Nanomaterials were used as modifiers to fabricate sensors and biosensors $[27,28]$ due to their novel optical, electrical, and catalytic properties, which result in high selectivity and sensitivity of any detection system $[29,30]$. By tuning the surface chemistry of nanostructured materials on the electrode, it could be directed towards the detection and capture of a certain analyte [31]. Presence of nanosized materials enhances electron transfer due to the increase of the electroactive surface area and promotes adsorption of molecules [32-34].

Recently, conducting porous layers modified electrodes were reported to improve the mass transport character from planar diffusion to thin layer; this change could shift the potential under which the target species undergo oxidation or reduction from that required to electrolyse the interfering species that facilitate the differentiation between species which oxidize or reduce at similar potentials under planar diffusion conditions $[5,6,35]$. Moreover, gold ( $\mathrm{Au}$ ) nanoporous has been attracting interest due to the wide range of applications that require inertness, conductivity, or increased surface area [7]. The immersion of nanoporous modified material in an electrolyte induces charges on the surface of a material because a potential is applied across the electrolyte/material interface, forming a capacitive double layer [8]. Recently, we have reported the development of nanoporous Au film modified Au electrodes and their applications for monitoring DA as well as cell-based chip [36, 37].

In the present work, we focus on developing nanoporous $\mathrm{Au}$ layer on $\mathrm{Au}$ electrode and its application as a sensor for selective electroanalytical detection of EP. The biosensor was fabricated based on electrochemical deposition of $\mathrm{Au}$ nanoporous layer onto $\mathrm{Au}$ electrode. The capability of nanosensor to selectively detect EP is evaluated in the presence of different interferences such as DA and UA. Herein, using nanoporous Au layer modified Au electrode in electrochemical detection of EP within a range from $1 \mathrm{mM}$ to $50 \mu \mathrm{M}$. The detection limit of our developed EP sensor in comparison with some examples of electrochemical sensors of EP based on modified electrodes was presented in Table 1, in addition to the detection of different concentrations of $\mathrm{EP}$ in the presence of DA and UA; the fabricated sensor was also applied to detect and quantify the mixture of EP and UA in human serum sample as real sample applications. Characteristics of the developed biosensor were investigated using cyclic voltammetric, SEM, calibration curves, and limit of detection of EP.

\section{Experimental}

2.1. Chemicals. Chloroauric acid tetrahydrate $\left(\mathrm{HAuCl}_{4}\right.$ $\cdot 4 \mathrm{H}_{2} \mathrm{O}$ ), trisodium citrate dehydrate, EP, DA, and UA were obtained from Sigma-Aldrich (3050 Spruce St, St. Louis, MO 63103, USA). Phosphate buffer solution (PBS) was prepared by using $0.1 \mathrm{M} \mathrm{Na} \mathrm{NPO}_{4}$ and $\mathrm{NaH}_{2} \mathrm{PO}_{4}$ and its $\mathrm{pH}$ was adjusted with $\mathrm{H}_{3} \mathrm{PO}_{4}$ or $\mathrm{NaOH}$ solutions.

2.2. Equipment. All electrochemical measurements were performed using micro-Autolab, potentiostat/galvanostat instrument (Netherlands) connected to a three-electrode cell; Metrohm Model 663VA stand was controlled by Autolab Nova software at room temperature. A three-electrode system consisted of a platinum wire as a counter electrode, $\mathrm{Ag} / \mathrm{AgCl}$ as the reference electrode, and modified Au substrate as a working electrode. The surface morphology was analyzed by SEM (ISISDS 130C, Akashi Co., Tokyo, Japan).

2.3. Electrochemical Measurements. The electrochemical measurements were carried out by immersing the fabricated modified Au electrode together with the reference and counter electrodes in the different concentrations of epinephrine ranging from $1 \mathrm{mM}$ to $50 \mu \mathrm{M}$; the solutions were prepared in different phosphate buffer solutions buffered ( $\mathrm{pH} 4,6$, and 9). Experiments were carried out to optimize all conditions in order to obtain the best cyclic voltammogram.

2.4. Fabrication of Mesoporous Gold Film. A $5 \mathrm{~nm}$ thick titanium layer and a $43 \mathrm{~nm}$ thick $\mathrm{Au}$ film were patterned one after the other on a glass substrate by DC magnetron 


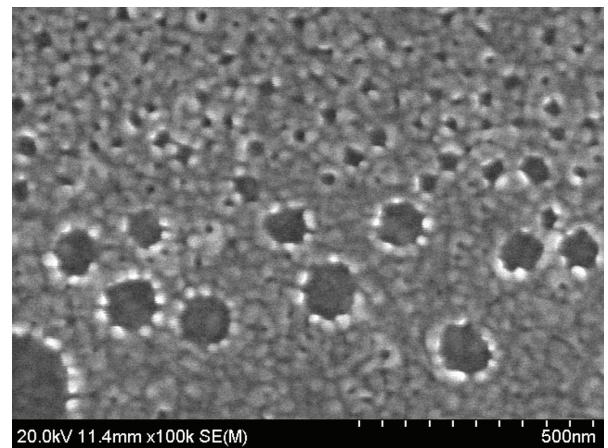

FIGURE 1: SEM image of Au nanoporous layer modified Au electrode.

sputtering. Bare Au electrodes were freshly cleaned using acidic piranha solution $\left(\mathrm{H}_{2} \mathrm{SO}_{4}: \mathrm{H}_{2} \mathrm{O}_{2}, 7: 3 \mathrm{v} / \mathrm{v}\right)$ and then rinsed thoroughly with deionized water (DIW) and dried under $\mathrm{N}_{2}$ gas. Then, the freshly cleaned Au electrodes $(2 \mathrm{~cm}$ $\times 1 \mathrm{~cm}$ ) were immersed in $5 \mathrm{~mL}$ of $1 \mathrm{mM}$ aqueous solution of $\mathrm{HAuCl}_{4}$ containing PEG $(20 \mu \mathrm{L} / \mathrm{mL})[13]$. Au nanoporous layer was electrochemical deposited at negative potential of $-1.3 \mathrm{~V}(\mathrm{Ag} / \mathrm{AgCl})$. Finally, the residue surfactant that might be adsorbed on the modified surface was removed by rinsing the substrates with DIW and then sonicated for 5 min with isopropyl alcohol. The surface morphologies were analyzed by scanning electron microscopy (SEM) (ISI DS130C, Akashi Co., Tokyo, Japan).

2.5. Selectivity of the Developed EP Sensor. The selectivity of the prepared electrode towards EP was studied by using mixture of EP solutions with different concentrations of dopamine and uric acid as interferences, which are commonly present in urine.

\section{Results and Discussion}

3.1. Characterization of Gold Modified Electrode. Morphology of the $\mathrm{Au}$ nanoporous film modified Au electrode that was fabricated based on electrodeposition method was characterized by using SEM as shown in Figure 1. The SEM demonstrated the deposition of monolayer nanoporous $\mathrm{Au}$ film with two sets of pore dimeters; one has pore dimeter of about $40 \mathrm{~nm}$ and the other sets have pore dimeter of about $100 \mathrm{~nm}$.

\subsection{Detection of Epinephrine Using Gold Modified Electrode.} The cyclic voltammetry study for $10^{-5} \mathrm{M}$ of EP solution (supporting electrolyte is sodium phosphate buffer of $\mathrm{pH}$ 7.0, 0.01 M) at Au nanosensor is presented in Figure 2. The voltammetric measurements were performed by scanning the potential within range from -0.7 to $+0.7 \mathrm{~V}$. The interaction of EP on the surface of the Au nanosensor resulted in an oxidation peak at $+0.2 \mathrm{~V}$ and a reduction peak at $-0.2 \mathrm{~V}$ due to the reduced quinone species as shown in Figure 3 [38]. The results obtained state the ability of the Au nanoporous monolayer immobilized on the Au electrode to efficiently catalyze the oxidation of EP. The use of Au modified electrode accelerates

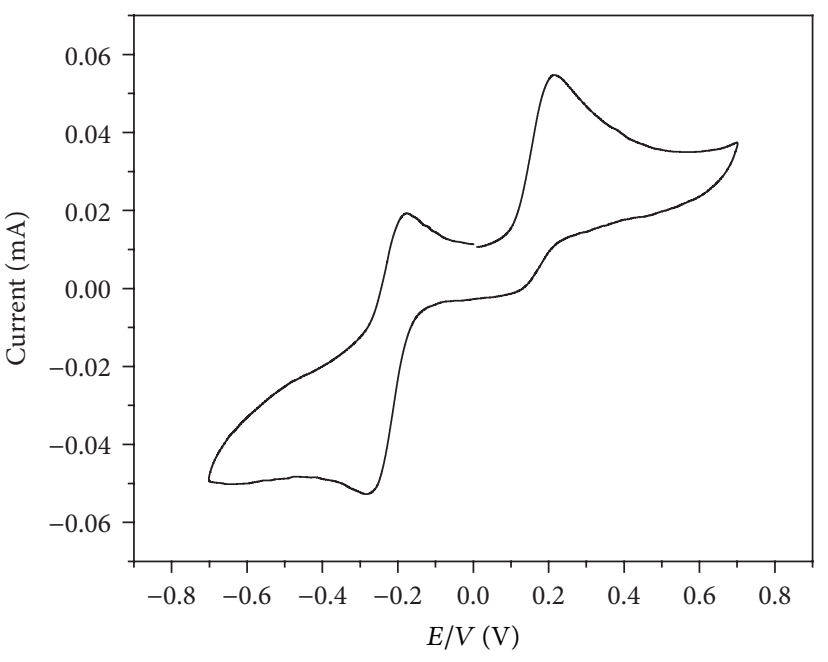

Figure 2: Cyclic voltammogram of epinephrine.

the electron transfer giving rise to a sharp oxidation and reduction peaks and also the high intensity as presented in Figure 2.

3.3. Effect of Different Epinephrine Concentrations. Cyclic voltammograms of different concentrations of epinephrine ranging from $1 \mathrm{mM}$ to $10 \mu \mathrm{M}$ at the Au nanoporous modified $\mathrm{Au}$ electrode are shown in Figure 4(a), which demonstrated that the redox current peaks were increased with increasing the concentration of EP. A linear response is obtained between the oxidation-reduction electrochemical peaks and the concentration of epinephrine where both of the electrochemical peaks increased with the increase of the concentration of epinephrine as presented in Figure 4(b). The limit of detection of the developed sensor was found to be $19 \mu \mathrm{M}$ that is in the same range of the detection limit for several reported sensors as shown in Table 1.

3.4. Dependence of $p H$. The electrochemical behavior of epinephrine was reported to be influenced by the acidity or alkalinity of the solution [50]. Effect of solution $\mathrm{pH}$ on the electrochemical behaviors was analyzed in PBS solutions of different $\mathrm{pH}(4,7$, and 9). A marked change is noticed in the electrochemical response of EP at Au nanosensor with the increase of $\mathrm{pH}$ value as in Figure 5. Figure 5 shows the important influence of change of the $\mathrm{pH}$ value on the redox reaction of $\mathrm{EP}$ at $\mathrm{Au}$ nanoporous modified $\mathrm{Au}$ electrode, which indicated that the redox peak was negatively shifted with increasing the $\mathrm{pH}$ value of the $\mathrm{pH}$ solution, which could be attributed to the uptake of electrons by an equal number of protons [51-53]. These results indicated the high dependence of the cyclic voltammograms response of $\mathrm{EP}$ on the $\mathrm{pH}$ of the solutions used as was shown in Figure 5.

3.5. Simultaneous Determination of Epinephrine and Uric Acid. Several chemically modified electrodes have been applied in the electrochemical and biological fields [6, 5459]. It is always of great importance to achieve the highest 
<smiles>CN[C@H](O)C1=CC(=O)C(=O)C=C1</smiles>

FIGURE 3: Oxidation mechanism of epinephrine.

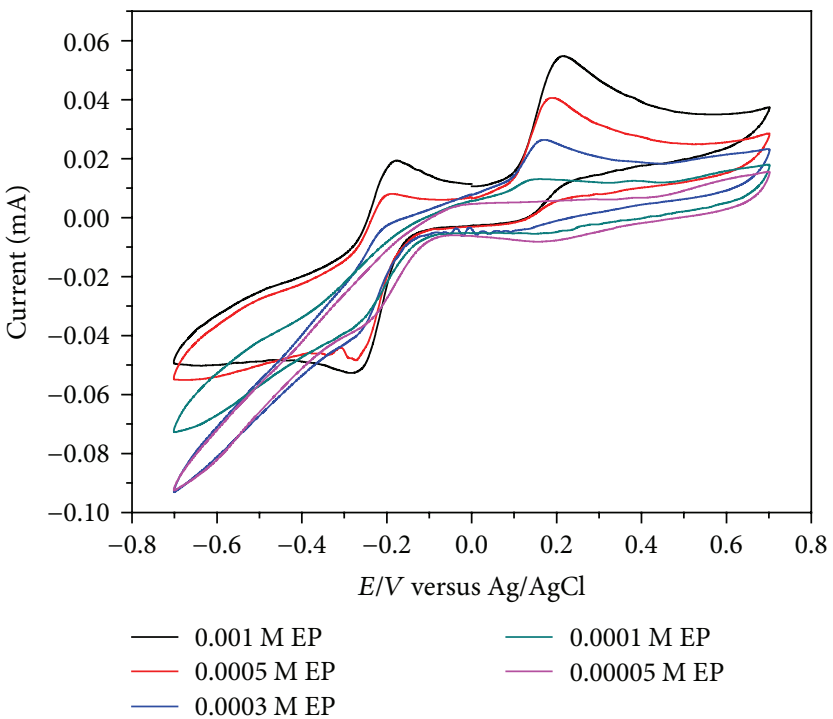

(a)

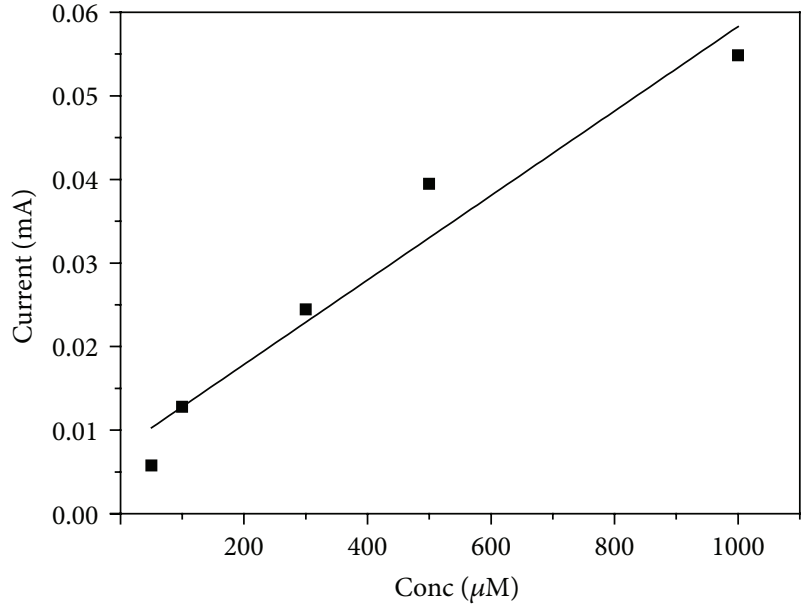

(b)

FIGURE 4: (a) Cyclic voltammogram of different concentrations of epinephrine and (b) linear relation between current and epinephrine concentrations.

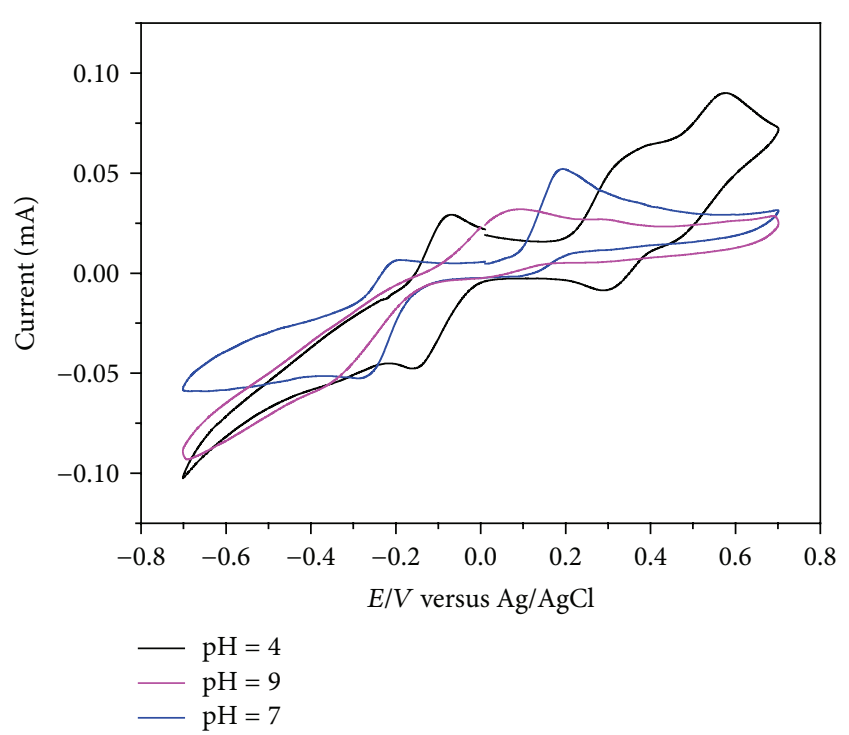

Figure 5: Cyclic voltammogram of the $\mathrm{pH}$ dependence of epinephrine.

selectivity and sensitivity towards neurotransmitters in presence of different interferences. Many difficulties have often faced the simultaneous detection of epinephrine, dopamine, and uric acid [7-9, 60]. Studies have been often developed towards the determination of a single component [61-63] due to overlapping of the voltammetric response of both DA and EP as a result to the similarities in their chemical structures. Our study is focused on the selective detection of EP in presence of uric acid which are frequently present together in biological systems and have no reduction peak. Figure 6 represented the CV of a mixture of EP and uric acid; a separation between the two cathodic peaks at $0.3 \mathrm{~V}$ and $0.5 \mathrm{~V}$ is obtained, respectively, which is enough to avoid any interference. According to the obtained results, the selective detection of epinephrine in presence of uric acid is applicable with sensitivity.

3.6. Application of Au Nanoporous Modified Au Electrode for Monitoring Epinephrine in Real Samples. In order to investigate the performance of the developed modified electrode to detect epinephrine in real samples, we have used human serum as a complex matrix. The application of the developed epinephrine sensor was studied by analyzing different concentrations of epinephrine in human serum that have been obtained from a healthy donor. Different epinephrine concentrations $(250,375$, and $500 \mu \mathrm{M})$ were spiked into $1 \%$ human serum and the mixed samples were analyzed. Figure 7 (a) shows the cyclic voltammograms of different epinephrine concentrations $(250,375$, and $500 \mu \mathrm{M})$ spiked 


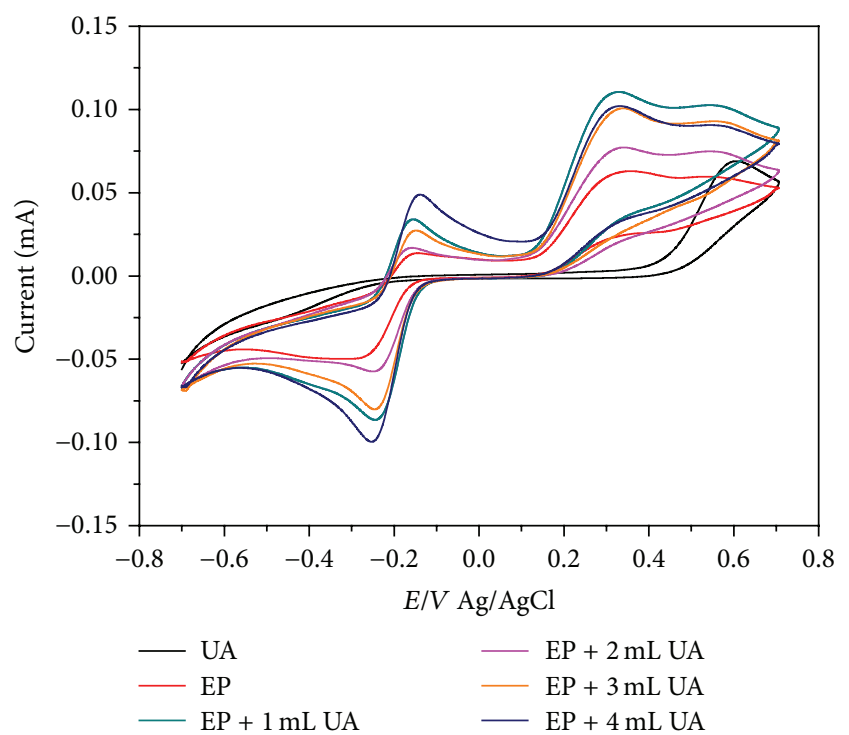

Figure 6: Cyclic voltammogram of epinephrine in presence of uric acid.

in serum, which exhibited similar electrochemical behavior epinephrine in PBS solution. This result indicated that the developed modified electrode could be applied for monitoring of epinephrine in real samples without interferences. Moreover, in biological environments, uric acid is commonly present with epinephrine and may be oxidized at similar potentials as epinephrine [64, 65]. Cyclic voltammograms of $2.5 \times 10^{-4}$ epinephrine mixed with $2.5 \times 10^{-4}$ uric acid and spiked in human serum sample were recorded as shown in Figure 7(b), which showed the ability of the electrode to distinguish epinephrine from uric acid in real sample since the oxidation peak of epinephrine was not affected by uric acid.

\section{Conclusions}

A new $\mathrm{Au}$ nanoporous modified $\mathrm{Au}$ electrode has been developed for epinephrine determination. The detection was performed by electroanalytical techniques by immersing the prepared electrode together with the reference and counter electrode in different epinephrine solutions and recording the cyclic voltammograms, which presented high sensitivity and low detection limit. The sensors show good reproducibility and excellent stability for more than six months. One important advantage is the marked peak separation between uric acid and epinephrine using Au nanoporous Au electrode indicating high selectivity. Application to real samples gave high sensitivity and selectivity of epinephrine.

\section{Competing Interests}

The authors declare that they have no competing interests.

\section{Acknowledgments}

This work was supported by Assiut University.

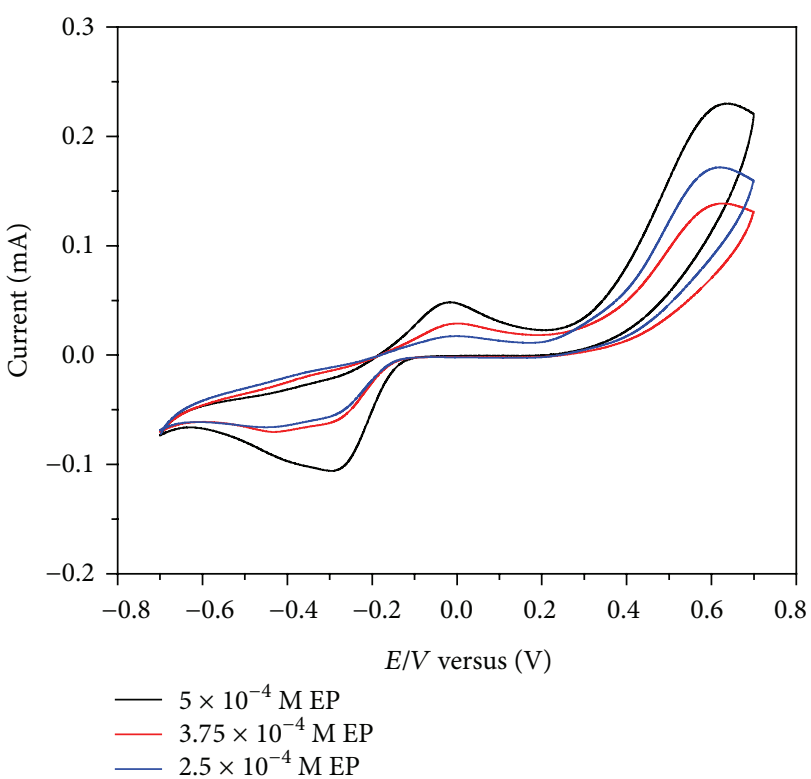

(a)

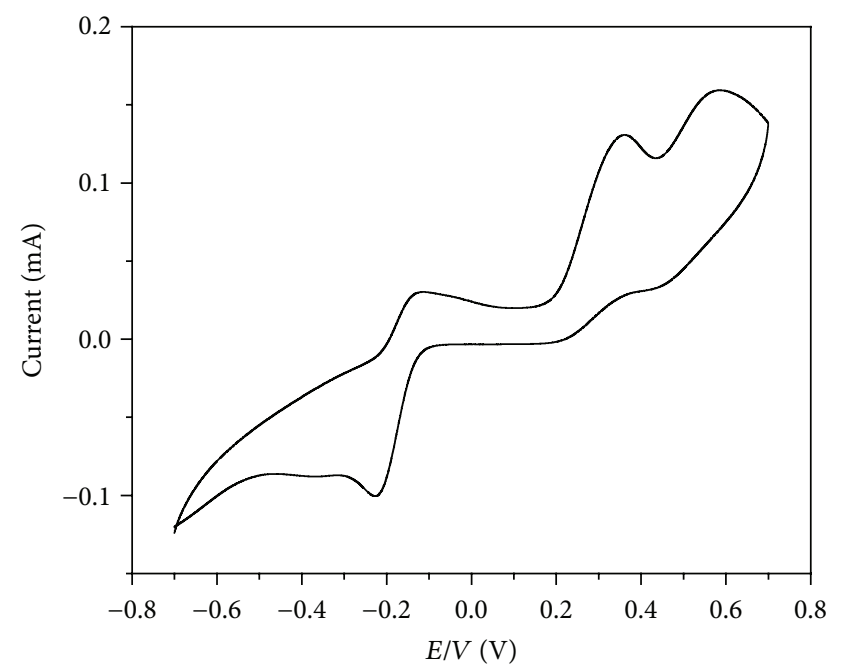

(b)

FIGURE 7: Cyclic voltammogram of (a) different concentrations of epinephrine in serum and (b) epinephrine in presence of uric acid in serum samples.

\section{References}

[1] T. Hashitani, K. Mizukawa, M. Kumazaki, and H. Nishino, "Dopamine metabolism in the striatum of hemiparkinsonian model rats with dopaminergic grafts," Neuroscience Research, vol. 30, no. 1, pp. 43-52, 1998.

[2] A. Carlsson, L. O. Hansson, N. Waters, and M. L. Carlsson, "Neurotransmitter aberrations in schizophrenia: new perspectives and therapeutic implications," Life Sciences, vol. 61, no. 2, pp. 75-94, 1997.

[3] J. W. Zheng, Y. Yang, S. H. Tian, J. Chen, F. A. W. Wilson, and Y. Y. Ma, "The dynamics of hippocampal sensory gating during the development of morphine dependence and withdrawal in rats," Neuroscience Letters, vol. 382, no. 1-2, pp. 164-168, 2005. 
[4] N. Nakao and T. Itakura, "Fetal tissue transplants in animal models of Huntington's disease: the effects on damaged neuronal circuitry and behavioral deficits," Progress in Neurobiology, vol. 61, no. 3, pp. 313-338, 2000.

[5] J. W. Mo and B. Ogorevc, "Simultaneous measurement of dopamine and ascorbate at their physiological levels using voltammetric microprobe based on overoxidized poly(1,2-phenylenediamine)-coated carbon fiber," Analytical Chemistry, vol. 73, no. 6, pp. 1196-1202, 2001.

[6] J. Wang and A. Walcarius, "Zeolite-modified carbon paste electrode for selective monitoring of dopamine," Journal of Electroanalytical Chemistry, vol. 407, no. 1-2, pp. 183-187, 1996.

[7] W. Ren, H. Q. Luo, and N. B. Li, "Simultaneous voltammetric measurement of ascorbic acid, epinephrine and uric acid at a glassy carbon electrode modified with caffeic acid," Biosensors and Bioelectronics, vol. 21, no. 7, pp. 1086-1092, 2006.

[8] M. D. Rubianes and G. A. Rivas, "Highly selective dopamine quantification using a glassy carbon electrode modified with a melanin-type polymer," Analytica Chimica Acta, vol. 440, no. 2, pp. 99-108, 2001.

[9] P. C. Pandey and B. C. Upadhyay, "Studies on differential sensing of dopamine at the surface of chemically sensitized ormosilmodified electrodes," Talanta, vol. 67, no. 5, pp. 997-1006, 2005.

[10] S. A. Ozkan, B. Dogan, and B. Uslu, "Voltammetric analysis of the novel atypical antipsychotic drug quetiapine in human serum and urine," Microchimica Acta, vol. 153, no. 1-2, pp. 2735, 2006.

[11] S. A. Özkan, B. Uslu, and Z. Sentürk, "Electroanalytical characteristics of amisulpride and voltammetric determination of the drug in pharmaceuticals and biological media," Electroanalysis, vol. 16, no. 3, pp. 231-237, 2004.

[12] S. A. Özkan, B. Uslu, and H. Y. Aboul-Enein, "Analysis of pharmaceuticals and biological fluids using modern electroanalytical techniques," Critical Reviews in Analytical Chemistry, vol. 33, no. 3, pp. 155-181, 2003.

[13] K. Jackowska and P. Krysinski, "New trends in the electrochemical sensing of dopamine," Analytical and Bioanalytical Chemistry, vol. 405, no. 11, pp. 3753-3771, 2013.

[14] N. F. Atta, A. Galal, and S. M. Azab, "Determination of morphine at gold nanoparticles/Nafion ${ }^{\circledR}$ carbon paste modified sensor electrode," Analyst, vol. 136, no. 22, pp. 4682-4691, 2011.

[15] B. J. Sanghavi, O. S. Wolfbeis, T. Hirsch, and N. S. Swami, "Nanomaterial-based electrochemical sensing of neurological drugs and neurotransmitters," Microchimica Acta, vol. 182, no. 1-2, pp. 1-41, 2015.

[16] W. A. El-Said, C.-H. Yea, H. Kim, B.-K. Oh, and J.-W. Choi, "Cell-based chip for the detection of anticancer effect on HeLa cells using cyclic voltammetry," Biosensors and Bioelectronics, vol. 24, no. 5, pp. 1259-1265, 2009.

[17] W. A. El-Said, T.-H. Kim, C.-H. Yea, H. Kim, and J.-W. Choi, "Fabrication of gold nanoparticle modified ITO substrate TO detect $\beta$-amyloid using surface-enhanced Raman scattering," Journal of Nanoscience and Nanotechnology, vol. 11, no. 1, pp. 768-772, 2011.

[18] N. Akhtar, S. A. El-Safty, M. Khairy, and W. A. El-Said, "Fabrication of a highly selective nonenzymatic amperometric sensor for hydrogen peroxide based on nickel foam/cytochrome $c$ modified electrode," Sensors and Actuators B: Chemical, vol. 207, pp. 158-166, 2015.

[19] W. A. El-Said, C.-H. Yea, J.-W. Choi, and I.-K. Kwon, "Ultrathin polyaniline film coated on an indium-tin oxide cell-based chip for study of anticancer effect," Thin Solid Films, vol. 518, no. 2, pp. 661-667, 2009.

[20] W. A. El-Said, J.-H. Lee, B.-K. Oh, and J.-W. Choi, "Electrochemical sensor to detect neurotransmitter using gold nano-island coated ITO electrode," Journal of Nanoscience and Nanotechnology, vol. 11, no. 7, pp. 6539-6543, 2011.

[21] W. A. El-Said and J.-W. Choi, "Electrochemical Biosensor consisted of conducting polymer layer on gold nanodots patterned Indium Tin Oxide electrode for rapid and simultaneous determination of purine bases," Electrochimica Acta, vol. 123, pp. 5157, 2014.

[22] W. A. El-Said, T.-H. Kim, H. Kim, and J.-W. Choi, "Detection of effect of chemotherapeutic agents to cancer cells on gold nanoflower patterned substrate using surface-enhanced Raman scattering and cyclic voltammetry," Biosensors and Bioelectronics, vol. 26, no. 4, pp. 1486-1492, 2010.

[23] J.-H. Lee, W. A. El-Said, B.-K. Oh, and J.-W. Choi, "Enzyme-free glucose sensor based on au nanobouquet fabricated indium tin oxide electrode," Journal of Nanoscience and Nanotechnology, vol. 14, no. 11, pp. 8432-8438, 2014.

[24] C. E. Banks, T. J. Davies, G. G. Wildgoose, and R. G. Compton, "Electrocatalysis at graphite and carbon nanotube modified electrodes: edge-plane sites and tube ends are the reactive sites," Chemical Communications, no. 7, pp. 829-841, 2005.

[25] F. Camacho-Alanis, L. Wu, G. Zangari, and N. Swami, "Molecular junctions of $\sim 1 \mathrm{~nm}$ device length on self-assembled monolayer modified n- vs. p-GaAs," Journal of Materials Chemistry, vol. 18, no. 45, pp. 5459-5467, 2008.

[26] X. Dai, O. Nekraseova, M. E. Hyde, and R. G. Compton, "Anodic stripping voltammetry of arsenic(III) using gold nanoparticlemodified electrodes," Analytical Chemistry, vol. 76, no. 19, pp. 5924-5929, 2004.

[27] R. M. Iost, J. M. Madurro, A. G. Brito-Madurro, I. L. Nantes, L. Caseli, and F. N. Crespilho, "Strategies of nano-manipulation for application in electrochemical biosensors," International Journal of Electrochemical Science, vol. 6, no. 7, pp. 2965-2997, 2011.

[28] C. Apetrei, I. M. Apetrei, J. A. de Saja, and M. L. RodriguezMendez, "Carbon paste electrodes made from different carbonaceous materials: application in the study of antioxidants," Sensors, vol. 11, no. 2, pp. 1328-1344, 2011.

[29] E. Katz, I. Willner, and J. Wang, "Electroanalytical and bioelectroanalytical systems based on metal and semiconductor nanoparticles," Electroanalysis, vol. 16, no. 1-2, pp. 19-44, 2004.

[30] C. M. Welch and R. G. Compton, "The use of nanoparticles in electroanalysis: a review," Analytical and Bioanalytical Chemistry, vol. 384, no. 3, pp. 601-619, 2006.

[31] N. S. Swami, C.-F. Chou, and R. Terberueggen, “Two-potential electrochemical probe for study of DNA immobilization," Langmuir, vol. 21, no. 5, pp. 1937-1941, 2005.

[32] S. Kochmann, T. Hirsch, and O. S. Wolfbeis, "Graphenes in chemical sensors and biosensors," TrAC-Trends in Analytical Chemistry, vol. 39, pp. 87-113, 2012.

[33] C. M. Li and W. Hu, "Electroanalysis in micro- and nano-scales," Journal of Electroanalytical Chemistry, vol. 688, pp. 20-31, 2012.

[34] Y. Shao, J. Wang, H. Wu, J. Liu, I. A. Aksay, and Y. Lin, "Graphene based electrochemical sensors and biosensors: a review," Electroanalysis, vol. 22, no. 10, pp. 1027-1036, 2010.

[35] W. Ahmed El-Said, C.-H. Yea, M. Jung, H. Kim, and J.-W. Choi, "Analysis of effect of nanoporous alumina substrate coated with polypyrrole nanowire on cell morphology based on AFM topography," Ultramicroscopy, vol. 110, no. 6, pp. 676-681, 2010. 
[36] W. A. El-Said, T.-H. Kim, H. Kim, and J.-W. Choi, "Threedimensional mesoporous gold film to enhance the sensitivity of electrochemical detection," Nanotechnology, vol. 21, no. 45, Article ID 455501, 2010.

[37] W. A. El-Said, J.-H. Lee, B.-K. Oh, and J.-W. Choi, "3-D nanoporous gold thin film for the simultaneous electrochemical determination of dopamine and ascorbic acid," Electrochemistry Communications, vol. 12, no. 12, pp. 1756-1759, 2010.

[38] T. Tavana, M. A. Khalilzadeh, H. Karimi-Maleh, A. A. Ensafi, H. Beitollahi, and D. Zareyee, "Sensitive voltammetric determination of epinephrine in the presence of acetaminophen at a novel ionic liquid modified carbon nanotubes paste electrode," Journal of Molecular Liquids, vol. 168, pp. 69-74, 2012.

[39] B. Zeng, Y. Yang, and F. Zhao, "Voltammetric determination of epinephrine with a 3-mercaptopropionic acid self-assembled monolayer modified gold electrode," Electroanalysis, vol. 15, no. 12, pp. 1054-1059, 2003.

[40] S. Shahrokhian and M. Khafaji, "Application of pyrolytic graphite modified with nano-diamond/graphite film for simultaneous voltammetric determination of epinephrine and uric acid in the presence of ascorbic acid," Electrochimica Acta, vol. 55, no. 28, pp. 9090-9096, 2010.

[41] R. Sadeghi, H. Karimi-Maleh, A. Bahari, and M. Taghavi, "A novel biosensor based on $\mathrm{ZnO}$ nanoparticle/1,3-dipropylimidazolium bromide ionic liquid-modified carbon paste electrode for square-wave voltammetric determination of epinephrine," Physics and Chemistry of Liquids, vol. 51, no. 6, pp. 704-714, 2013.

[42] S. Shahrokhian, M. Ghalkhani, and M. K. Amini, "Application of carbon-paste electrode modified with iron phthalocyanine for voltammetric determination of epinephrine in the presence of ascorbic acid and uric acid," Sensors and Actuators, B: Chemical, vol. 137, no. 2, pp. 669-675, 2009.

[43] L. Wang, J. Bai, P. Huang, H. Wang, L. Zhang, and Y. Zhao, "Electrochemical behavior and determination of epinephrine at a penicillamine self-assembled gold electrode," International Journal of Electrochemical Science, vol. 1, pp. 238-249, 2006.

[44] H. Yaghoubian, H. Beitollah, V. Soltani-Nejad et al., "Simultaneous voltammetric determination of epinephrine and acetaminophene at the surface of modified carbon nanotube paste electrode," International Journal of Electrochemical Science, vol. 6, no. 5, pp. 1307-1316, 2011.

[45] M. E. Ghica and C. M. A. Brett, "Simple and efficient epinephrine sensor based on carbon nanotube modified carbon film electrodes," Analytical Letters, vol. 46, no. 9, pp. 1379-1393, 2013.

[46] S. S. Shankar and B. E. K. Swamy, "Detection of epinephrine in presence of serotonin and ascorbic acid by TTAB modified carbon paste electrode: A Voltammetric Study," International Journal of Electrochemical Science, vol. 9, no. 3, pp. 1321-1339, 2014.

[47] H. Zhou, G. Xu, A. Zhu et al., "A multiporous electrochemical sensor for epinephrine recognition and detection based on molecularly imprinted polypyrrole," RSC Advances, vol. 2, no. 20, pp. 7803-7808, 2012.

[48] M. Devendiran, J. Kavitha, and S. S. Narayanan, "Development of an electrochemical amperometric sensor for the determination of epinephrine using MWCNT/dopamine dithiocarbamate modified electrode," International Journal Innovative Research in Science \& Engineering.
[49] E. Wierzbicka and G. D. Sulka, "Fabrication of highly ordered nanoporous thin $\mathrm{Au}$ films and their application for electrochemical determination of epinephrine," Sensors and Actuators, B: Chemical, vol. 222, pp. 270-279, 2016.

[50] T. Łuczak, "Epinephrine oxidation in the presence of interfering molecules on gold and gold electrodes modified with gold nanoparticles and thiodipropionic acid in aqueous solution. A Comparative Study," Electroanalysis, vol. 21, no. 23, pp. 25572562, 2009.

[51] M. D. Hawley, S. V. Tatawawadi, S. Piekarski, and R. N. Adams, "Electrochemical studies of the oxidation pathways of catecholamines," Journal of the American Chemical Society, vol. 89, no. 2, pp. 447-450, 1967.

[52] H. S. Wang, D. E. Huang, and R. M. Liu, "Study on the electrochemical behavior of epinephrine at a poly(3-methylthiophene)-modified glassy carbon electrode," Journal of Electroanalytical Chemistry, vol. 570, no. 1, pp. 83-90, 2004.

[53] W. Ma and D. M. Sun, "The electrochemical properties of dopamine, epinephrine and their simultaneous determination at a poly(L-methionine) modified electrode," Russian Journal of Electrochemistry, vol. 43, no. 12, pp. 1382-1389, 2007.

[54] C. W. Xu, R. Zeng, P. K. Shen, and Z. D. Wei, "Synergistic effect of $\mathrm{CeO}_{2}$ modified $\mathrm{Pt} / \mathrm{C}$ catalysts on the alcohols oxidation," Electrochimica Acta, vol. 51, no. 6, pp. 1031-1035, 2005.

[55] T. Inoue and J. R. Kirchhoff, "Electrochemical detection of thiols with a coenzyme pyrroloquinoline quinone modified electrode," Analytical Chemistry, vol. 75, no. 18, pp. 4942-4942, 2003.

[56] E. Bustos, J. Manríquez, G. Orozco, and L. A. Godínez, "Preparation, characterization, and electrocatalytic activity of surface anchored, Prussian Blue containing starburst PAMAM dendrimers on gold electrodes," Langmuir, vol. 21, no. 7, pp. 3013-3021, 2005.

[57] H. Gu, X. d. Su, and K. P. Loh, "Electrochemical impedance sensing of DNA hybridization on conducting polymer filmmodified diamond," The Journal of Physical Chemistry B, vol. 109, no. 28, pp. 13611-13618, 2005.

[58] J. Wang, M. Musameh, and Y. Lin, "Solubilization of carbon nanotubes by Nafion toward the preparation of amperometric biosensors," Journal of the American Chemical Society, vol. 125, no. 9, pp. 2408-2409, 2003.

[59] V. Mirčeski, F. Quentel, M. L'Her, and F. Scholz, "Studying the coupled electron-ion transfer reaction at a thin film-modified electrode by means of square-wave voltammetry," Journal of Electroanalytical Chemistry, vol. 586, no. 1, pp. 86-97, 2006.

[60] H.-M. Zhang, X.-L. Zhou, R.-T. Hui, N.-Q. Li, and D.-P. Liu, "Studies of the electrochemical behavior of epinephrine at a homocysteine self-assembled electrode," Talanta, vol. 56, no. 6, pp. 1081-1088, 2002.

[61] S. H. Kim, J. W. Lee, and I.-H. Yeo, "Spectroelectrochemical and electrochemical behavior of epinephrine at a gold electrode," Electrochimica Acta, vol. 45, no. 18, pp. 2889-2895, 2000.

[62] V. S. Bezerra, J. L. L. Filho, M. C. B. S. M. Montenegro, A. N. Araújo, and V. L. Silva, "Flow-injection amperometric determination of dopamine in pharmaceuticals using a polyphenol oxidase biosensor obtained from soursop pulp," Journal of Pharmaceutical and Biomedical Analysis, vol. 33, no. 5, pp. 10251031, 2003.

[63] D. R. Shankaran, N. Uehara, and T. Kato, "Sol-gel derived metal dispersed ceramic-graphite composite electrode for amperometric determination of dopamine," Analytica Chimica Acta, vol. 478, no. 2, pp. 321-327, 2003. 
[64] Y.-X. Sun, S.-F. Wang, X.-H. Zhang, and Y.-F. Huang, "Simultaneous determination of epinephrine and ascorbic acid at the electrochemical sensor of triazole SAM modified gold electrode," Sensors and Actuators, B: Chemical, vol. 113, no. 1, pp. 156-161, 2006.

[65] K. L. Thomas, J. P. Piccini, L. Liang et al., "Racial differences in the prevalence and outcomes of atrial fibrillation among patients hospitalized with heart failure," Arrhythmia and Electrophysiology, vol. 2, Article ID e000200, 2013. 

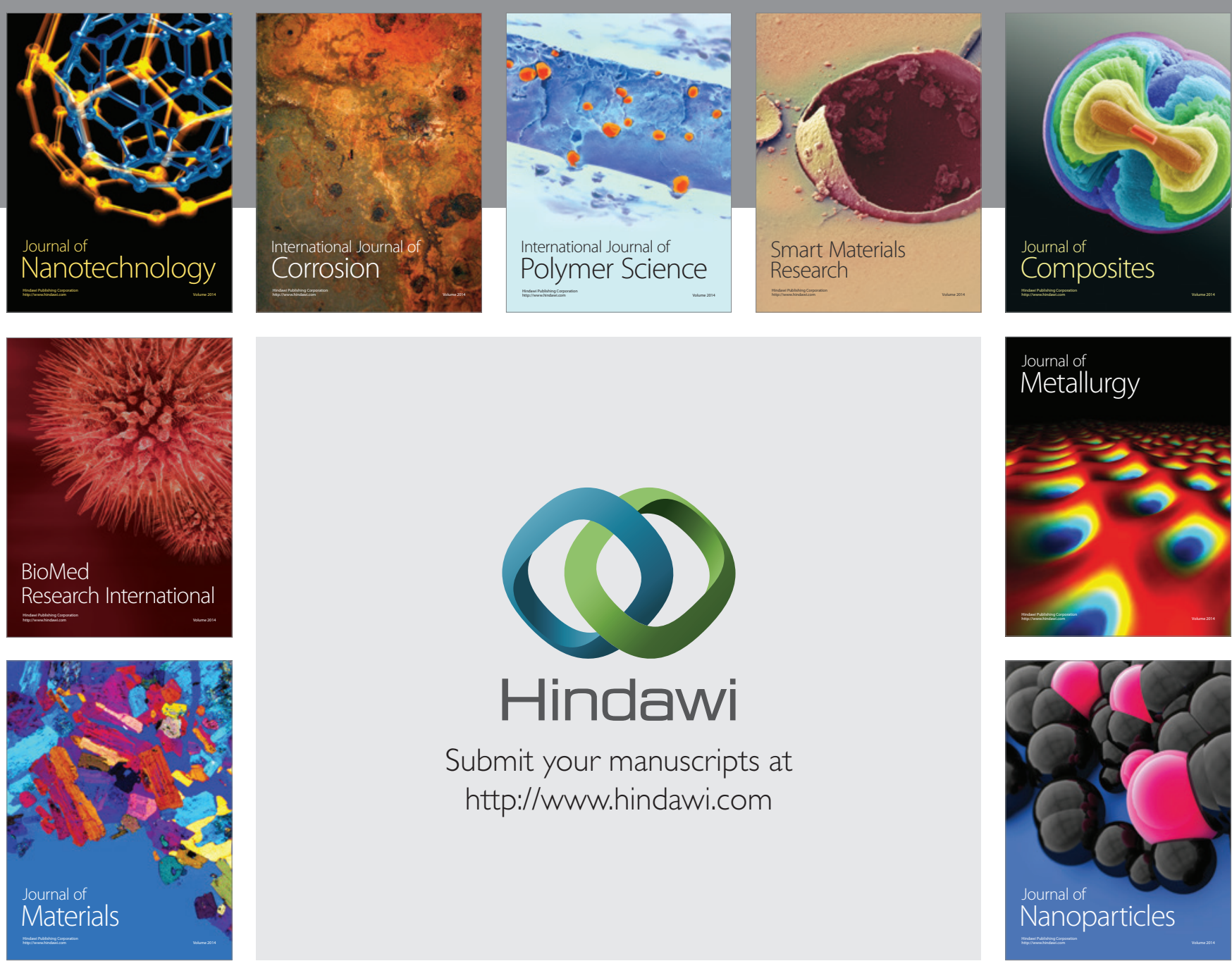

\section{Hindawi}

Submit your manuscripts at

http://www.hindawi.com

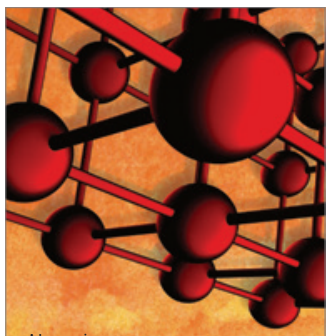

Materials Science and Engineering
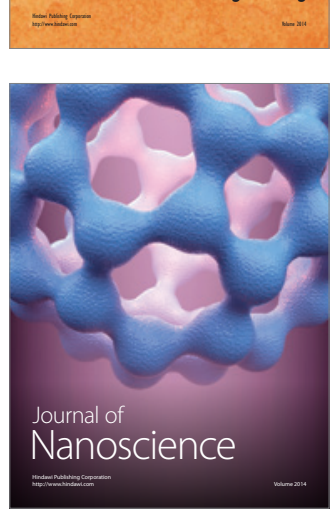
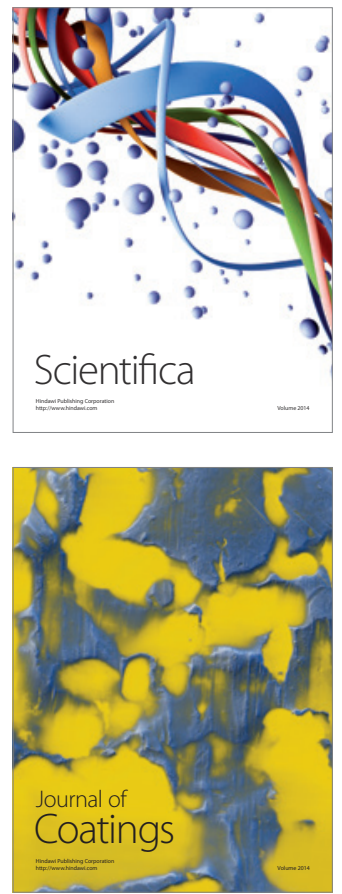
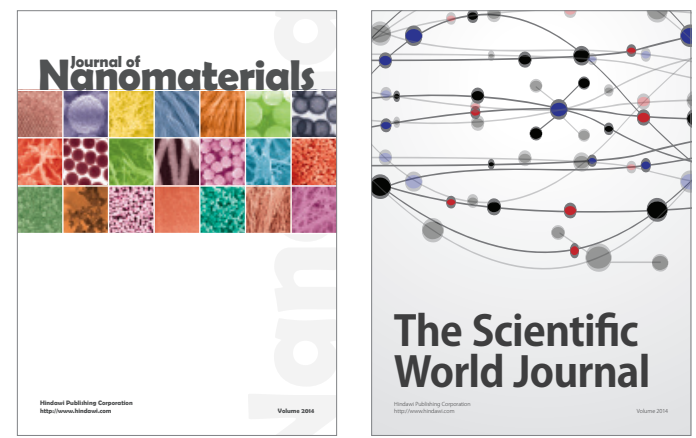

The Scientific World Journal
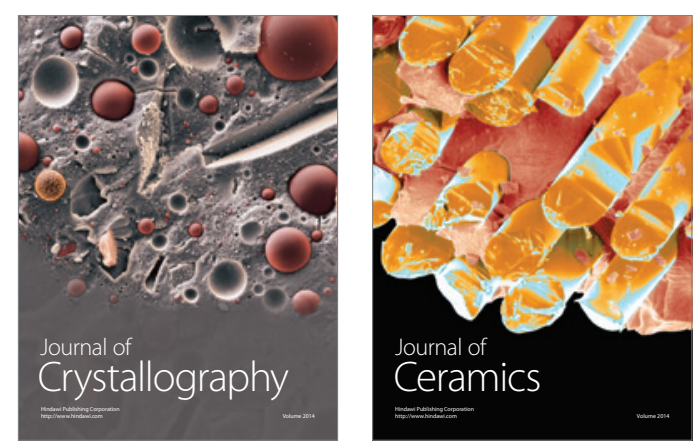
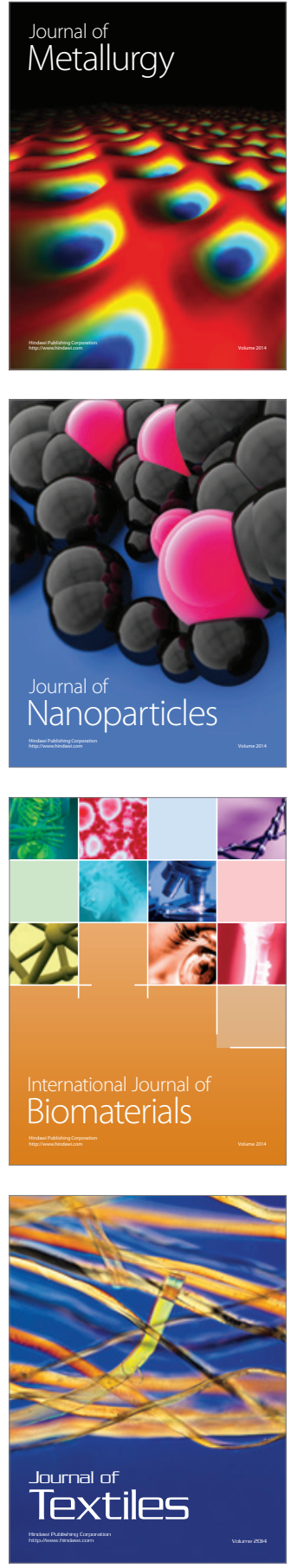